\title{
THERMO-MECHANICAL FATIGUE ANALYSIS OF A STEAM TURBINE SHAFT
}

\author{
Martin NesládeK ${ }^{a, *}$, Josef Jurenka ${ }^{a}$, Michal BartošáK $^{a}$, \\ Milan RŮŽičKa ${ }^{a}$, MAXim Lutovinov ${ }^{a}$, JAN PAPUgA ${ }^{a}$, RAdeK Procházka ${ }^{b}$, \\ JAN DŽUGAN ${ }^{b}$, PETR MĚŠŤÁNEK ${ }^{c}$ \\ ${ }^{a}$ Czech Technical University in Prague, Faculty of Mechanical Engineering, Technická 4, 166 07 Prague 6, Czech \\ Republic \\ ${ }^{b}$ COMTES FHT a.s., Prưmyslová 995, 33441 Dobřany, Czech Republic \\ ${ }^{c}$ Doosan Škoda Power s.r.o., Tylova 1/5\%, 30128 Plzeř, Czech Republic \\ * corresponding author: martin.nesladek@fs.cvut.cz
}

\begin{abstract}
Increasing demands on the flexibility of steam turbines due to the use of renewable energy sources substantially alters the fatigue strength requirements of components of these devices. Rapid start-ups as well as the increased number of the load cycles applied to the turbines must be handled by design methodologies. The goal of the work presented in this paper was to provide a computational framework applicable to the thermo-mechanical fatigue (TMF) prediction of steam turbine shafts. The so-called Damage Operator Approach by Nagode et al. has been implemented to the software codes and applied to fatigue analysis of the thermo-mechanical material response computed numerically by the finite element analysis. Experimental program conducted in order to identify the material thermo-mechanical behavior and to verify numerical simulations is introduced in the paper. Some results of TMF prediction of a sample steam turbine shaft are shown.
\end{abstract}

KEYWORDS: Fatigue prediction, thermo-mechanical fatigue, finite element analysis, Chaboche elasticplastic model.

\section{INTRODUCTION}

The energy industry has been experiencing significant changes recently. The overall share of renewable sources in the European Union countries has reached 17 percent [1]. The leading country in this statistic is Sweden having more than 50 percent of energy from renewable sources. In Czech Republic it is approximately 15 percent and the overall trend is that this share will continue to grow significantly in the future - the EU strategy is to reach at least $27 \%$ by 2030 .

However, instability of the power output due to the nature of the renewable sources may cause problems in energy supplies if it is not compensated by some back-up sources. Currently, there are no reliable ways to save energy for power shortages in the network in a sufficiently large scale. This role must be taken over by traditional thermal power sources such as gas-fired power plants providing "just-in-time" energy supplies. The problem is that these plants already have to or will have to cover shortages in the daily regime. Increased number of start-ups and shut-downs as long as increasing demands on speed-up of the start-ups set new challenges in the gas and steam turbine design.

Components of steam turbines are often exposed to thermo-mechanical loading due to variable thermal and mechanical loading conditions induced by the turbine start-ups and shut-downs. The main damage mechanisms, which if they occur together constitute the therm "thermo-mechanical faigue" (TMF), are often referred to as oxidation, mechanical fatigue and creep [2, 3]. Constitutive material model derived from the material testing, finite element analysis and suitable fatigue criterion is required for the reliable damage assessment of components subjected to cyclic thermo-mechanical loading conditions. This work is focused on the TMF assessment of a sample case of a steam turbine shaft. Motivation for this work originates from the need for revising the current steam turbine design strategies due to the above-mentioned reasons.

Classical low-cycle fatigue (LCF) criteria as SmithWatson-Topper (SWT) 4 and the Nihei [5] methods in their original form can only cope with isothermal loading. For the case of thermo-mechanical loading, cycle reference temperature, which could be used to select fatigue curves for the isothermal models, is somewhat arbitrary and error-prone.

The so-called Damage Operator Approach (DOA) by Nagode et al. [6, 7] overcomes this issue by introducing a procedure for continuous damage parameter calculation. In the original form it is based on the SWT method, however the damage induced by nonstationary thermal and mechanical loading is evaluated in a chronological manner, i.e. damage is computed and accumulated in any time point no matter if it is load reversal or not. Such approach allows for handling arbitrary thermal and mechanical load 
sequences without the need for evaluating the abovementioned cycle reference temperature.

The work presented here was done within the Flexturbine project, which aims to revise the design of key turbine components and propose new design methodologies so that the turbines can cope with the changing situation in the transmission grids. The paper describes the approach to prediction of thermomechanical fatigue of steam turbine shafts. Especially the high-pressure sections of turbine shafts are exposed to complex thermo-mechanical loading due to variable service conditions.

Within the experimental part of the work, experiments for identifying parameters of the selected constitutive model as well as parameters of damage model were carried out. The assumed constitutive model of the material mechanical response is temperaturedependent elastic-plastic and for the purpose of the structural finite element analysis (FEA) parameters of the Chaboche non-linear kinematic hardening were identified. The DOA allows for processing stress histories computed by FEA in order to perform correction on the material viscous behavior, if needed. Strain controlled fatigue tests with hold period may be used for finding the parameters of the Maxwell model of viscoplasticity, which may then be applied for evaluating the viscous strain and subsequent stress relaxation.

A set of TMF tests for verifying the prediction methodology have been scheduled. Various phasing of temperature and mechanical load is tested. The experiments are conceived as strain-controlled with two channels of strain applied to tubular specimens axial and torsional. TMF test setup is briefly introduced in the paper and some preliminary results are presented. Thermo-mechanical stress-strain response from the tests and numerical simulations is compared.

The elastic-plastic material model is used in the structural FEA of the steam turbine shaft, which is performed on the basis of the simulated temperature fields that are obtained from the previous transient thermal FEA. Finite element calculations for the steam turbine shaft are performed in the commercial finite element software. Subsequently, TMF is predicted for the turbine shaft on the basis of the calculated stress, strain and temperature histories.

\section{EXPERIMENTAL WORK}

As mentioned within the introduction section, the experimental work may be divided into two main groups depending on the general purpose of the individual test - on the one hand basic material tests to identify parameters of constitutive models and on the other hand tests intended for verifying the proposed modeling methodology. The material subjected to testing was a chrome-molybdenum creep resistant steel applicable to steam turbine shafts.

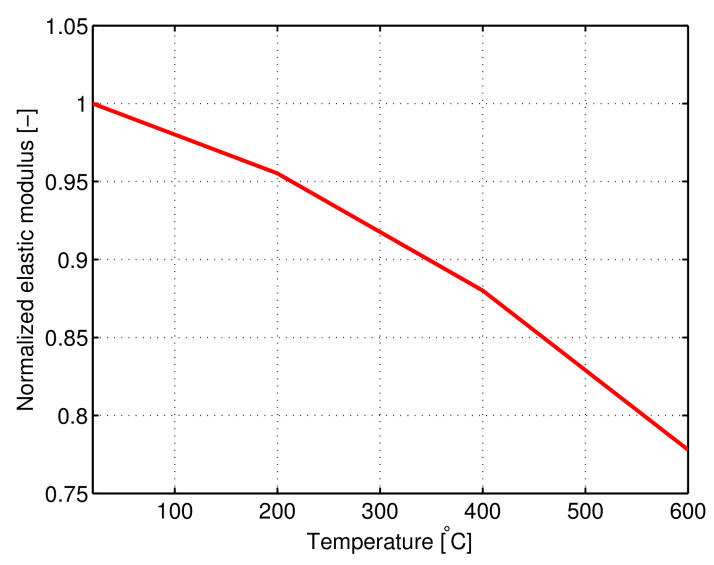

Figure 1. The temperature dependent Young's modulus.

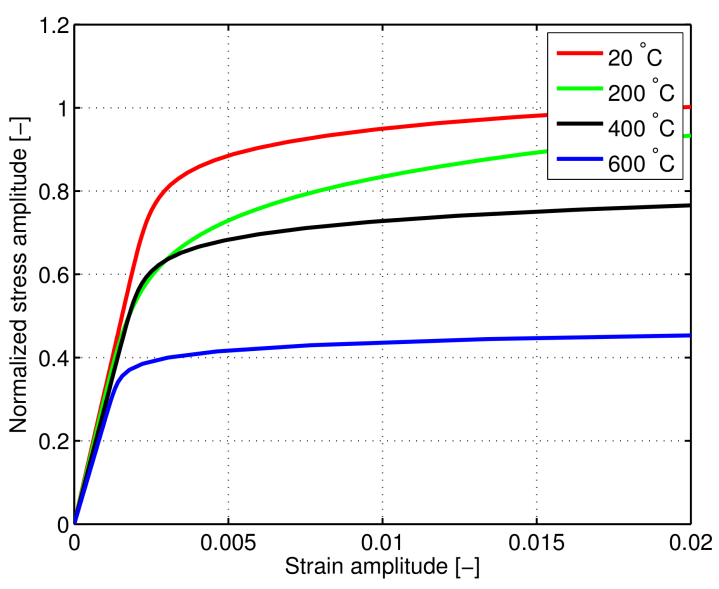

Figure 2. The temperature dependent cyclically stable cyclic stress-strain curves.

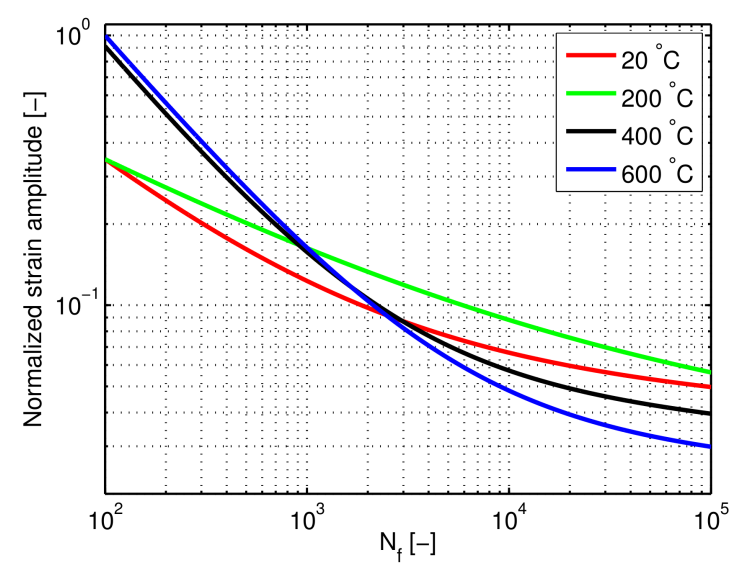

Figure 3. The temperature dependent Manson-Coffin and Basquin curves. 


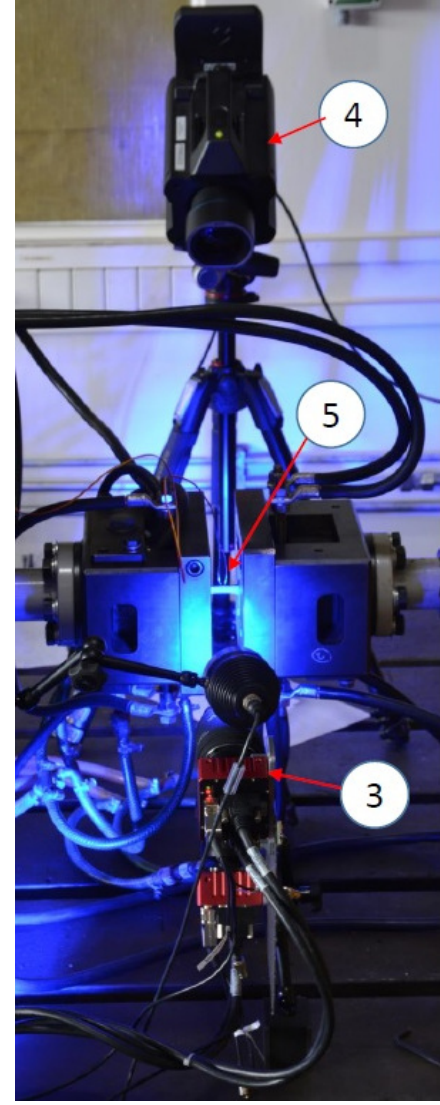

(A) . Detail of grips with the test specimen and instrumentation

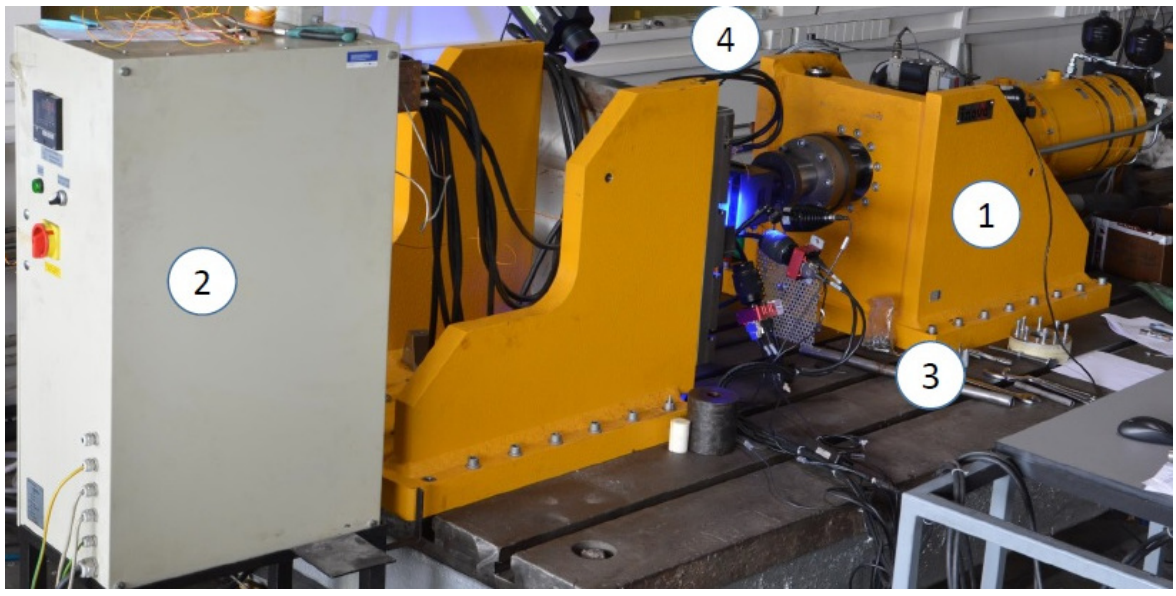

(в) . Overall view of the TMF test setup

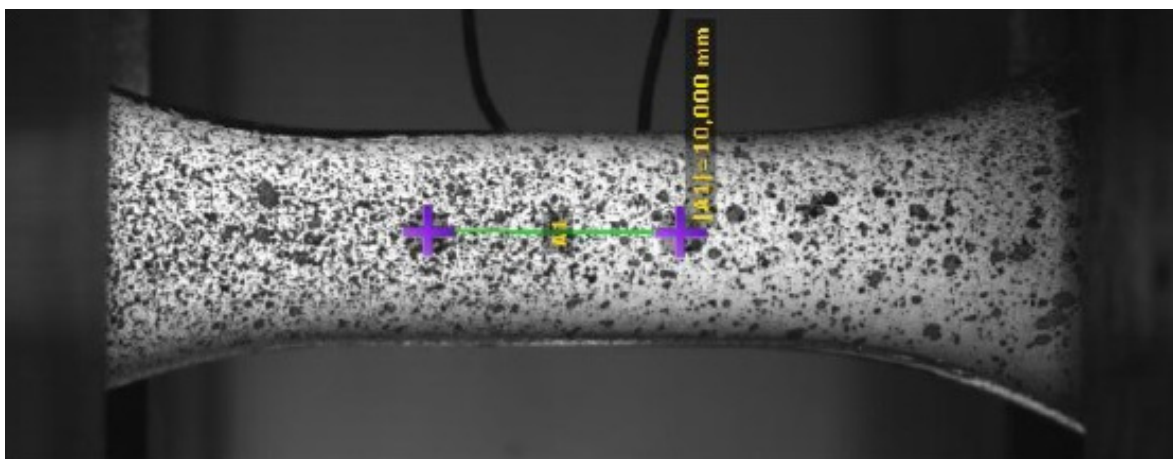

(c) . Tubular test specimen with surface speckle pattern and welded thermocouple

Figure 4. TMF test setup and specimen. 1 - servohydraulic axial-torsional test machine, 2 - resistance heating, 3 camera of the DIC system, 4 - infrared camera, 5 - test specimen.

\subsection{BASIC MECHANICAL MATERIAL TESTS}

Static tensile tests as well as LCF tests under the isothermal conditions have been carried out. The assumed temperature range of the tests was $20-600{ }^{\circ} \mathrm{C}$, which correspond to operating conditions of the sample steam turbine. Circular specimens with $10 \mathrm{~mm}$ diameter in the gauge section have been tested. Radiant heating of specimens was controlled by a split furnace. As a minimum, ten samples have been tested on each curve.

Fig. 1, 2 and 3 show the main results of the isothermal material tests, i.e. temperature dependent normalized Young's modulus, cyclic stress-strain curves (CSSCs) and the Manson-Coffin and Basquin curves, respectively. The Young's modulus and the CSSCs have been used for identifying the elastic-plastic material model based on the Chaboche's procedure section 3

The temperature dependent Manson-Coffin and Basquin curves are used as an input to the DOA. Numerical procedure based on this approach is described in section 4

LCF strain-controlled tests with hold period have been performed in order to identify temperature de-

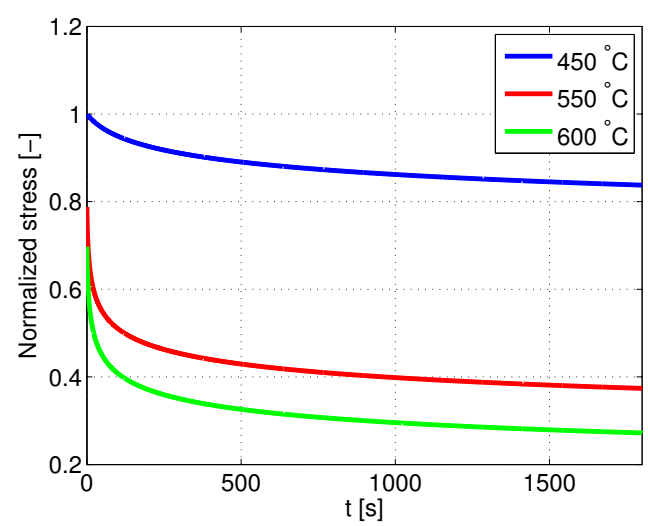

Figure 5. The temperature dependent stress relaxation curves.

pendent stress relaxation curves - Fig. 5 This is an important input to the DOA allowing for separating elastic-plastic and viscous strain and modeling stress relaxation - section 4. Note that the curves in Fig. 5 are shown for illustrative purposes and will be further refined with continuation of the experimental program. 


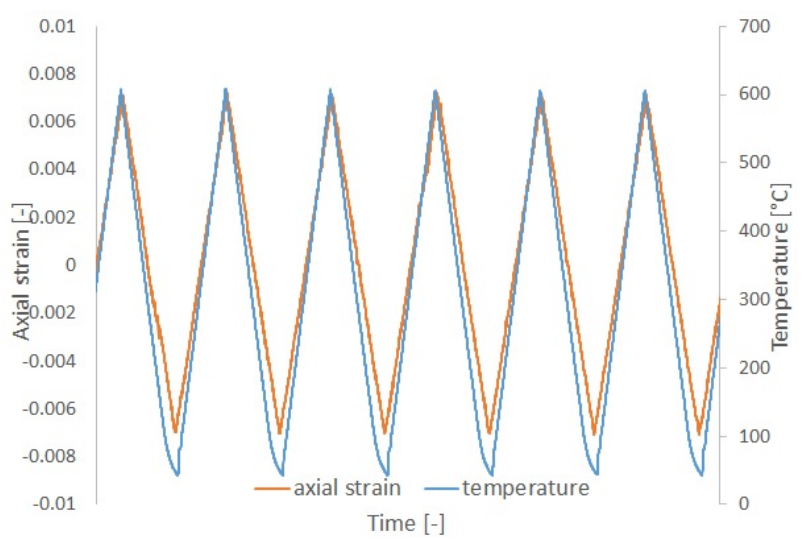

Figure 6. Time dependence of axial strain and temperature during the in-phase TMF test.

Furthermore, creep tests should be conducted in order to identify constants of the Larson-Miller parameter that is applied to evaluating creep damage.

\subsection{VERIFICATION TESTS}

Experimental setup for TMF tests is shown in Fig. $4 \mathrm{a}$ and $4 \mathrm{~b}$. The test machine is equipped with a servohydraulic actuator allowing for combined axial and torsional loading. Resistance heating is applied to specimens and the induced temperature is controlled by a thermocouple welded in the center of the specimen gauge section. Online axial and torsional deformation control is done by an optical measurement system based on the digital image correlation (DIC). Tubular specimens with $8.5 \mathrm{~mm}$ in diameter and $0.75 \mathrm{~mm}$ wall thickness of the gauge section are sprayed with temperature-stable paint creating a random speckle pattern - Fig. 4c Design of the test specimens conforms to ASTM E2207 standard.

Triangular strain and temperature in-phase and out-of-phase loading is assumed within the tests - Fig. 6 and 7. Until now, tests with axial strain loading at $\varepsilon_{a}=0.007$ and $R=-1$ have been conducted. The maximum test temperature is $600{ }^{\circ} \mathrm{C}$. More tests combining axial and torsional loading with various phases are scheduled in order to check the prediction quality of the selected model.

\section{Numerical Simulations}

\subsection{Constitutive material model}

A constitutive material model must be able to describe the cyclic material behavior for the service temperature range of the steam turbine shaft. The temperature-dependent Chaboche non-linear kinematic hardening model [8, 9] is selected for the elasticplastic FEA.

The yield criterion may be expressed as

$$
f(\boldsymbol{\sigma}-\boldsymbol{\alpha})=k,
$$

where $k$ is the material temperature dependent yield stress, $\boldsymbol{\sigma}$ is the stress tensor and $\boldsymbol{\alpha}$ denotes the back-

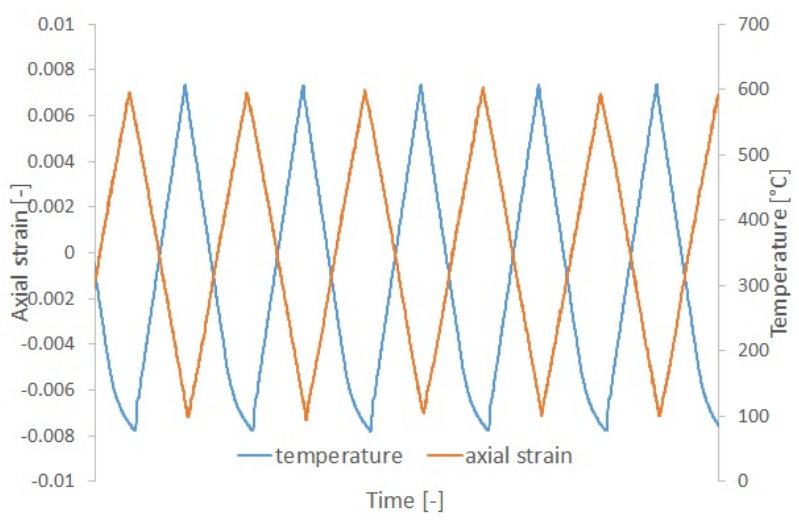

Figure 7. Time dependence of axial strain and temperature during the out-of-phase TMF test.

stress tensor. The function $f()$ denotes the von Mises stress norm, which may be in this case evaluated as

$$
f(\boldsymbol{\sigma}-\boldsymbol{\alpha})=\sqrt{\frac{3}{2}\left(\boldsymbol{S}-\boldsymbol{\alpha}^{\prime}\right):\left(\boldsymbol{S}-\boldsymbol{\alpha}^{\prime}\right)},
$$

where $\boldsymbol{S}$ and $\boldsymbol{\alpha}^{\prime}$ are the deviatoric parts of the stress and the backstress tensors, respectively. The : operator denotes the tensor contraction. Assuming the non-linear kinematic hardening model, the total backstress is composed of multiple backstress components as follows:

$$
\boldsymbol{\alpha}=\sum_{i} \boldsymbol{\alpha}_{i}
$$

The non-isothermal evolution of the backstress components is defined as:

$$
\dot{\boldsymbol{\alpha}}_{i}=\frac{2}{3} C_{i} \dot{\boldsymbol{\varepsilon}}_{p}-\gamma_{i} \boldsymbol{\alpha}_{i} \lambda+\frac{1}{C_{i}} \frac{\partial C_{i}}{\partial T} \boldsymbol{\alpha}_{i} \dot{T}
$$

$C_{i}$ and $\gamma_{i}$ are temperature dependent material parameters, which may be derived from the material mechanical cyclic stress-strain response. $\varepsilon_{p}$ is the plastic strain tensor and $\lambda$ is accumulated plastic strain. In our case, the model with three backstress terms was selected, where $\gamma_{3}$ is assumed constant and equal to zero.

Plots in Fig. 8 and 9 show comparison of the measured temperature-dependent material mechanical response with the one simulated by finite elements using the above-mentioned constitutive model. The plots show good agreement of simulated and experimentally determined material response.

\subsection{FEA OF A STEAM TURBine ShaFt}

The non-linear transient elastic-plastic FEA of a sample steam turbine shaft has been carried out in order to investigate local thermo-mechanical material response due to the turbine load regimes. In this paper, results of the cold-start load scenario are presented. At first, transient thermal analysis has to be conducted in order to analyze the time-dependent temperature spatial 


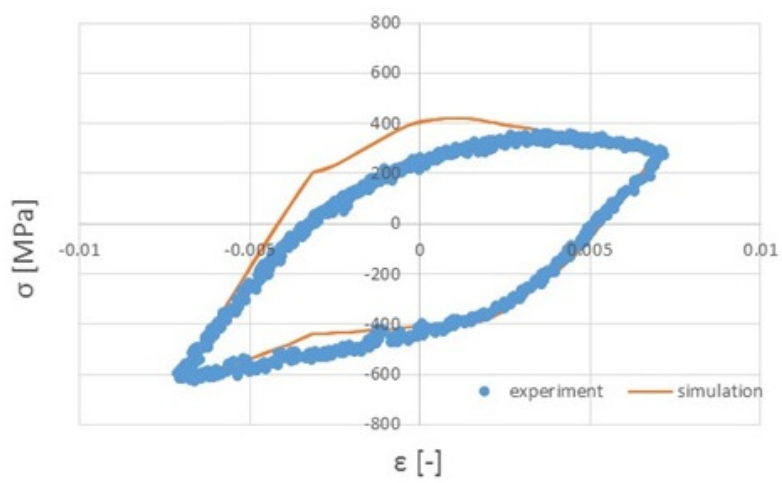

Figure 8. Comparison of measured and simulated mechanical response due to in-phase uniaxial mechanical and thermal loading.

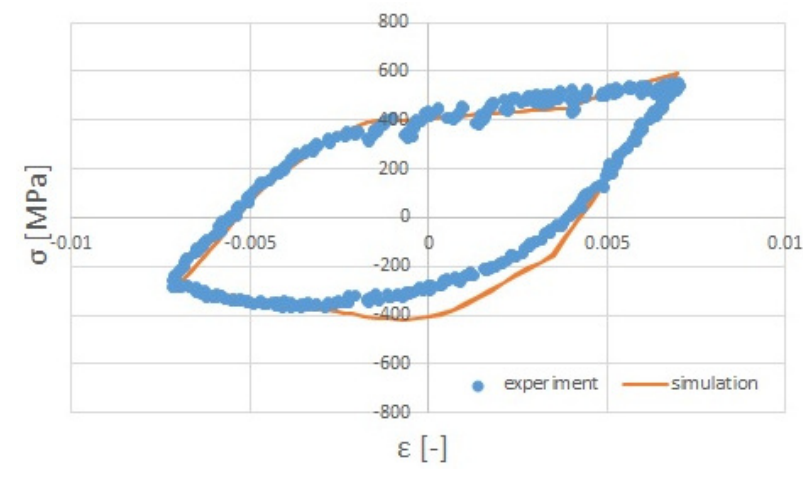

Figure 9. Comparison of measured and simulated mechanical response due to out-of-phase uniaxial mechanical and thermal loading.

distribution. The cold-start regime is characterized by the turbine start-up from ambient temperature and after shut-down it cools down back to almost $20{ }^{\circ} \mathrm{C}$. So the service temperature range corresponds to $\sim 20-600{ }^{\circ} \mathrm{C}$ and especially during the start-up process the material exhibits severe temperature gradients in the subsurface layers since it is exposed to superheated steam. The heating rates are the matter of the individual turbine design that has to ensure that the material fatigue strength corresponding to the expected turbine life is not exceeded. Three basic turbine load regimes are assumed in the design - cold, warm and hot starts differing, from a material point of view, in the initial temperature and allowable heating rates. However, regarding the necessary computation strategy, these regimes are similar.

Temperature distribution in the turbine is a function of complex time evolution of heat flux governed by the material surface and steam flow difference and heat transfer coefficients. The induced thermal gradients result in the constrained material expansion with pronounced thermal stresses. Furthermore, mechanical loads due to shaft rotation and steam flow pressure on blade airfoils have to be taken into account.

Fig. 10 shows time and subsurface distribution of thermo-mechanical material response within a single cold-start cycle in the domain marked in Fig. 10a. The observable discontinuities in temperature are present due to the step changes in the boundary conditions, which partly reflect the nature of the service conditions. On the other hand, this also partly results from modeling imperfections caused by higher analysis incrementation than would be suitable to cover some steep transients. However, this is a reasonable compromise between accuracy and solution cost.

The plots in Fig. 10 illustrate how complex the material thermo-mechanical response could be in such structure. For instance, in the R3 notch root the cyclic plastic stress-strain state under variable temperature is present. This justifies selection of the DOA as a method to assessing the TMF damage.

\section{Thermo-Mechanical Fatigue PREDICTION}

Fig. 11 graphically presents the main steps, inputs and outputs of the DOA, which was adopted and implemented to software codes for the purpose of this work. As mentioned in the introduction section, the main advantage of this approach is that it treats thermo-mechanical material response in step-by-step manner (i.e. in increment-by-increment manner if translated into the finite element terminology). This allows for handling arbitrary stress-strain and temperature histories in TMF prediction, while assigning the proper parameters of the material damage model to the individual load time points.

In general, it requires local elastic-plastic stress and temperature from FEA as an input. The material inputs are temperature-dependent CSSCs, MansonCoffin and Basquin curves, Larson-Miller parameter and stress relaxation curves for cases, where the material viscous effect is substantial. Note that $d=1 / N$ denotes mechanical fatigue damage per single cycle. Prandtl hysteresis operator is employed in order to model the continuous fatigue mechanical damage influenced by temperature changes. The total damage is evaluated as summation of the mechanical part and the creep part computed separately. The oxidation effect is treated indirectly since the material fatigue and creep tests are performed under environmental conditions. Palmgren-Miner's rule [10] and Robnson's life-fraction rule [11] are used for accumulating the mechanical fatigue and creep damage, respectively.

This procedure has been coded to an in-house $\mathrm{C}++$ procedure allowing for processing thermo-mechanical response from FEA. Refer to [12] for more details.

\section{Results AND DisCUSSION}

TMF prediction results obtained by the DOA are shown in Fig. 12 and Tab. 1. The contour plot in Fig. $12 \mathrm{~b}$ shows distribution of $\sqrt[6]{D}$ quantity, where $D$ denotes the TMF damage due to the cold-start turbine load regime. It may be observed that the critical place is the R3 domain. Note that these results were obtained by the DOA without taking the 


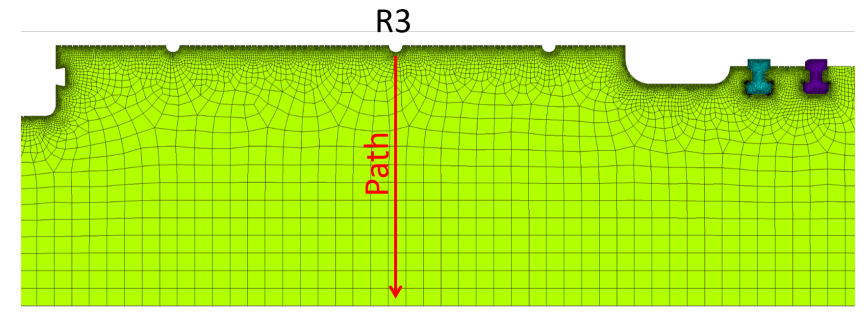

(A) . The R3 domain and direction of the nodal path from which the results below have been extracted.

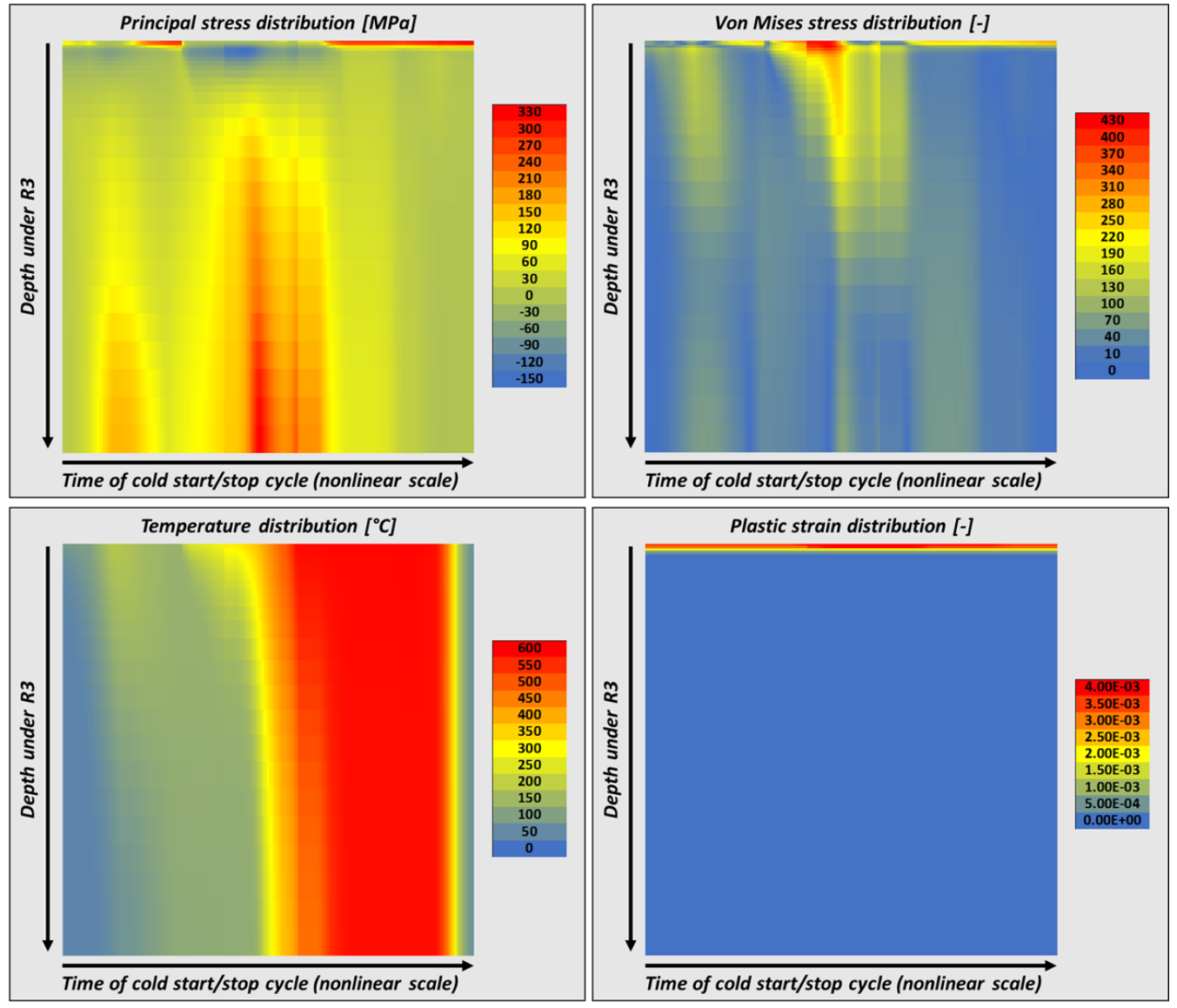

(B) . Time and spatial distribution of thermo-mechanical material response in the R3 domain.

FIGURE 10. FEA results in the R3 domain of the sample steam turbine shaft.

\begin{tabular}{lcccccc}
\hline & R2 & R3 & R4 & R5 & HP1 upper fillet & HP1 lower fillet \\
\hline TMF damage & $1.31 \cdot 10^{-4}$ & $2.66 \cdot 10^{-4}$ & $1.69 \cdot 10^{-4}$ & $2.11 \cdot 10^{-4}$ & $2.25 \cdot 10^{-5}$ & $1.81 \cdot 10^{-4}$ \\
TMF life & 7633 & 3759 & 5917 & 4739 & 44444 & 5525 \\
\hline
\end{tabular}

TABLE 1. TMF fatigue prediction results by the DOA in the selected domains of the steam turbine. 


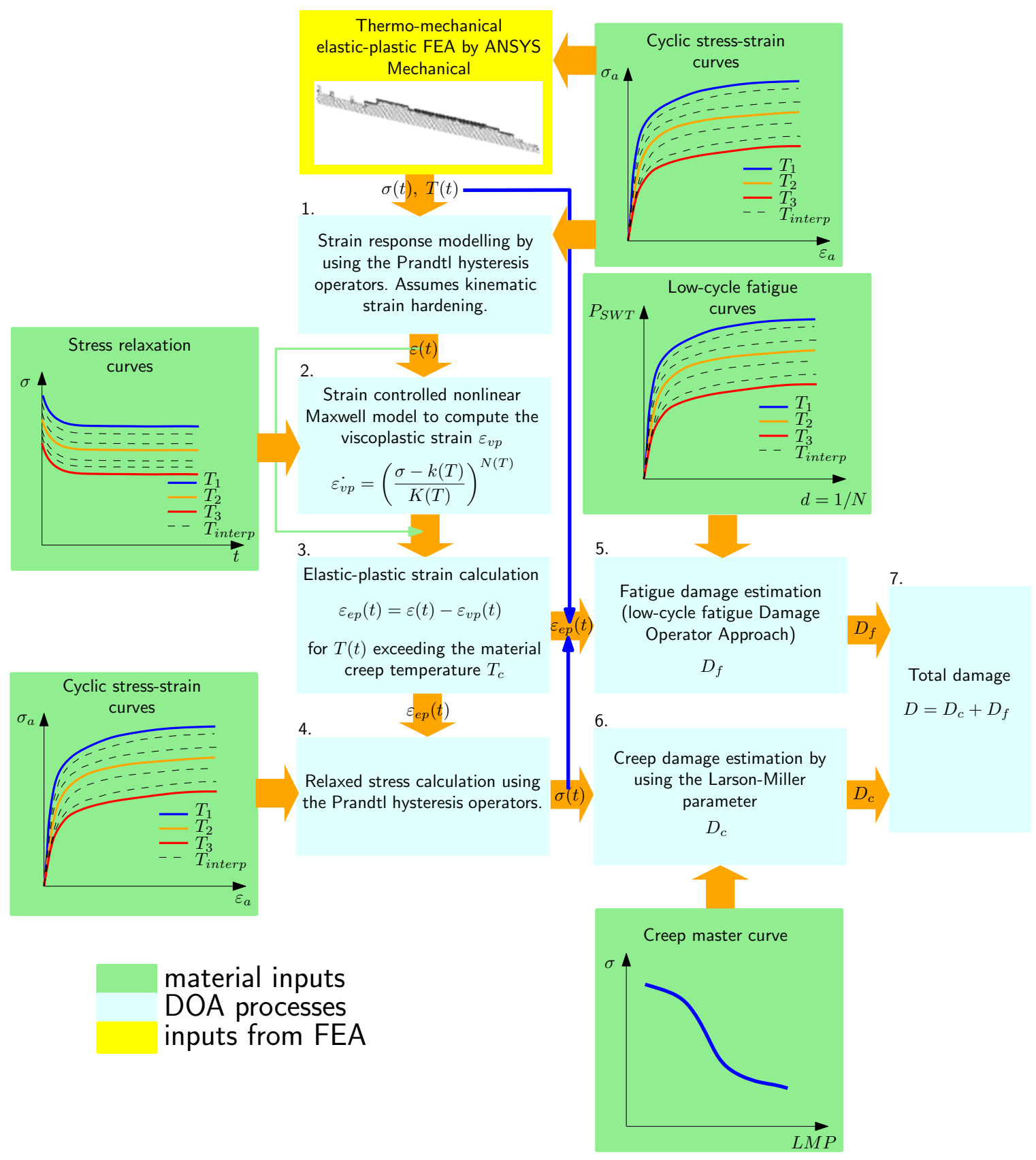

Figure 11. Flowchart to illustrate the basics of the Damage Operator Approach by Nagode et al. 


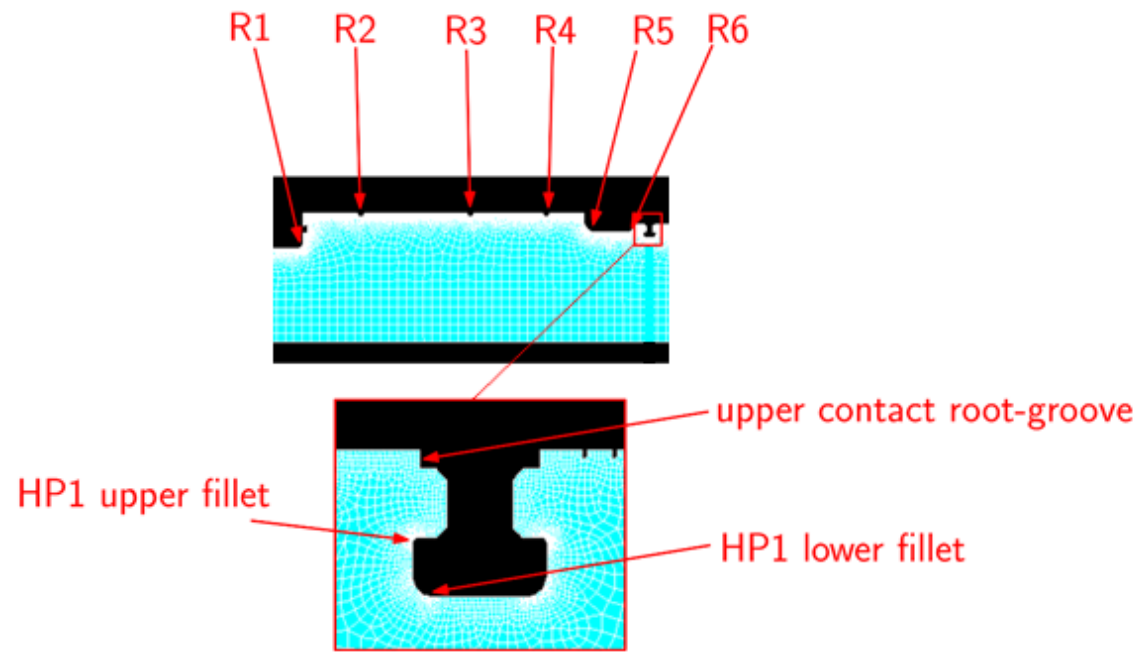

(A) . Steam turbine domain nomenclature adopted in this paper.

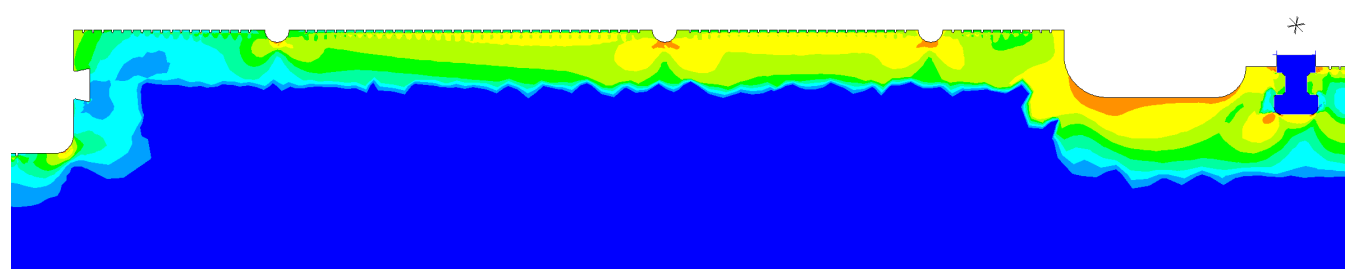

(в) . Sample contour plot of TMF damage distribution analyzed by the DOA in the main sealing part of the steam turbine.

FiguRE 12. TMF prediction by the DOA.

material viscoplasticity into account. The difference between these values and those presented in [12] is due to different approach to handling the stress-strain histories. The results presented in this paper have been evaluated by using only the signed von Mises stress from the FEA as an input to the DOA. The mechanical strain values have been obtained by using the Prandtl hysteresis operators, which are part of the DOA - Fig. 11. This approach gives a stress-strain response that more closely matches the physical behavior of the material than the approach that had been used in 12 . In that previous paper, the signing was applied to both the stress and the strain histories extracted from FEA. This naturally may lead to distorted hysteresis loops and may have resulted to, for instance, different stress means and amplitudes. If these stress and strain histories are used as a direct input to the function evaluating the TMF damage, different results may be obtained as well.

\section{Conclusions}

This paper briefly presents the experimental program conducted in order to provide the necessary material and verification data for the adopted TMF approach. The TMF experimental setup was introduced and the experimentally determined stress-strain response was compared to the simulated one. The comparison shows good agreement of both experimental and numerical data. The DOA in the form allowing for the viscous correction of strain histories and stress relaxation has been implemented to the software codes and the results of the TMF prediction on the sample steam turbine shaft are presented in the text.

\section{ACKNOWLEDGEMENTS}

This project has received funding from the European Union's Horizon 2020 research and innovation program under the Grant Agreement No. 653941.

\section{REFERENCES}

[1] Share of renewables in energy consumption in the EU reached $17 \%$ in 2016. http://ec.europa.eu/eurostat/ documents/2995521/8612324/8-25012018-AP-EN.pdf/ 9d28caef-1961-4dd1-a901-af18f121fb2d Accessed: 2018-07-30.

[2] R. W. Neu, H. Sehitoglu. Thermomechanical Fatigue, Oxidation and Creep: Part I. Damage Mechanisms. Metall Trans A 20(9A):1755-1767, 1989.

[3] R. W. Neu, H. Sehitoglu. Thermomechanical Fatigue, Oxidation and Creep: Part II. Life Prediction. Metall Trans A 20(9A):1769-1783, 1989.

[4] K. N. Smith, P. Watson, T. H. Topper. A Stress-Strain Function for the Fatigue of Metals. $J$ Mater, JMLSA 5(4):767-778, 1970.

[5] M. Nihei, P. Heuler, C. Boller, T. Seeger. Evaluation of Mean Stress Effect on Fatigue Life by Use of Damage Parameters. Int J Fatigue 8(3):119-126, 1986. 
[6] M. Nagode, F. L angler, M. Hack. A Time-Dependent Damage Operator Approach to Thermo-mechanical Fatigue of Ni-resist D-5S. Int J Fatigue 33(5):692-699, 2011. DOI:https://doi.org/10.1016/j.ijfatigue.2010.11.009

[7] M. Nagode. Continuous Damage Parameter Calculation under Thermomechanical Random Loading. MethodsX 1:81-89, 2014. https://doi.org/10.1016/j.mex.2014.07.004

[8] J. L. Chaboche. Time-Independent Constitutive Theories for Cyclic Plasticity. Int J Plasticity 2(2):149-188, 1986.

[9] J. L. Chaboche. Constitutive Equations for Cyclic Plasticity and Cyclic Viscoplasticity. Int J Plasticity 5(3):247-302, 1989.
[10] A. Palmgren. Die Lebensdauer von Kugellagern. Zeitschrift des Vereines Deutscher Ingenieure 68(14):339-341, 1924.

[11] E. L. Robinson. Effect of Temperature Variation on the Long-Time Rupture Strength of Steels. Trans ASME 74:777-780, 1952.

[12] M. Nesládek, M. Bartošák, J. Jurenka, et al. Thermo-Mechanical Fatigue Prediction of a Steam Turbine Shaft. MATEC Web Conf 165, 2018. https://doi.org/10.1051/matecconf/201816522016 